\title{
43 二つの二次元自由噴流の衝突に関する研究
}

\author{
東京工科第二専門学校 \\ 自動車科 \\ 長沢浩二 \\ 松崎進一 \\ study on the impingement of two turbulent plane free jets \\ By Koji NAGASAWA and Shinichi MATSUzAKI

\begin{abstract}
This paper presents an experimental study on impingement of two turbulent plane free jets. Flow visualization by dry-ice vaporing method, the effects of impinging angle and velocity ratio on the concentration were investigated. As a result of this study, it is found that the mass transfer differs from the momentum transfer slightly and the concentration distributions are not similer as yet.
\end{abstract}

1.ま紊がき

産業の各方面では、利用される流れが噴流状を呈していたり、または噴流状の流れをより積 極的に利用することがしばしば見受けられる。例えば河川への温排水、純流体素子内の流れ、 ウォータージェット技術、内燃機関関保などさまさまな分野に応用されている。しかし噴流 と噴流の重笑に関しては、その利用例があるにも拘らず流れの複雑さともあいまって、これま であまり研究されてきていない。著者の一人は先に二つの二次元自由噴流の衝垁実驗を行い、 合流噴流の流れ方向は二つの噴流のノスル出口における全運動量と衝突角によって決まること が確かめられ、また衝突後の速度. 静圧分布なども测定している。しかし衝突による互いの噴 流の粒子の混合、いわゆる乱流混合と拡散がいかになされるのか等の詳しいことはまだ不明な 点が多い。そしてこれらに関する研究は円管開口部からの乱流物質拡散の測定などが散見され るだけである。

そこで本研笢では二つ の二次元噴流を種々の角 度と速度比で酎笑させた 時、二つの流れがどのよ うに混合していくのかの 解明の糸口として、ドラ イアイス蒸気法による俚 突点付近の可視化を行。 た。これによりその後行 つた合流賈流の濃度分布 測定のための概略をつか もうとしたものてある。

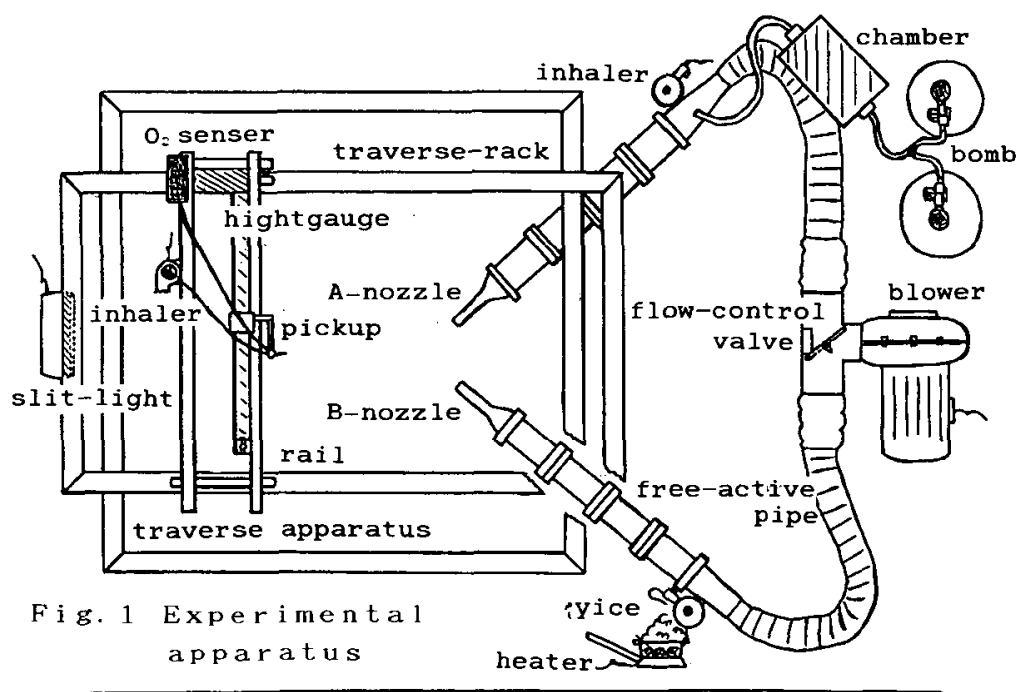

ه Tokyo Technical College, 1-1-21 Kamata Setagaya-ku Tokyo 157. 


\section{2 . 実験装置と実験方法}

実験装置は図1に示される。装置全体は横置きとし、衝突角と衝突位置はガイドレールによ り容易に任意に変更できる。ブロワーからの流れはフローコントロールバルブにより任意の速 度比 $\mathrm{U}_{\mathrm{B}} / \mathrm{U}_{\mathrm{A}}$ に設定でき、メッシュ、ハニーカムなどを通り幅 $\mathrm{d}=20 \mathrm{~m} \mathrm{~m}$ (アスペクト比

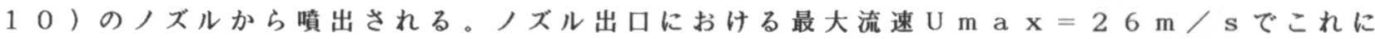
対するレイノルス数 $\mathrm{R}$ e $\mathrm{m} \mathrm{a} \mathrm{x}=3.8 \times 10^{4}$ であった。

流れの可視化のためのドライアイス蒸気は流速が比較的速いため多量に必要であり、粉砕し たドライアイスを熱湯にそそいで発生させ拡散筒部に設置した吸引装置により流れに混入した 。幅 $5 \mathrm{~mm}$ mスリット光源は下流から照射した。また濃度測定は一方の流れに铚素を混入し、 噴流の各断面において吸引部 开のピトー静圧管を取付け、ゲッチンゲンマノメーターにより測定した。写真撮影条件は絞 り 2. 8、シャッ夕ースピード1/15〜1/30、A S A 400 を使用した。

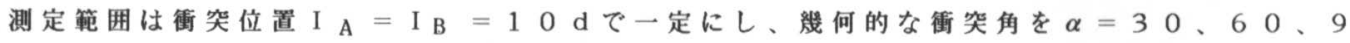
$0 、 120$ 度に変えた。各々に対し速度比 $U_{B} / U_{A}$ を三種類に変えた。得られたデータは一 旦ティスクに記憶、保存し、必要に応じてパソコン処理しクラフ化などを行いプリントアウト した。

\section{3. 実驗結果と考察}

3. 1 流れの可視化写真 1,2 は $\alpha=30 \cdot 、 \mathrm{U}_{\mathrm{B}} / \mathrm{U}_{\mathrm{A}}=1.1$ の同一条件で片側又は両 側にドライアイス蒸気を混入したものである。これより衝笑後の各々の噴流境界付近で相互の 流体の貫流混合がみられるが、それは完全ではなくかなり下流まで続く。(文献 4 参照) 写真 3,4 は $\alpha=60^{\circ} 、 \mathrm{U}_{\mathrm{B}} / \mathrm{U}_{\mathrm{A}}=1.3,1.5$ の場合で特に写真 4 の片側にドライアイス 混入の場合に示されるように、流速の遅い側の流れの一部は速い側の境界に沿って巻上がり、 そこで他方に巻込まれていく。写真 $5 ， 6$ は $\alpha=90^{\circ}$ で $\mathrm{U}_{\mathrm{B}} / \mathrm{U}_{\mathrm{A}}=0.8,1.2$ の場合で 写真 6 からは明らかな上流側への分割流が生している。写真 7 は $\alpha=1200^{\circ}$ で $\mathrm{U}_{\mathrm{B}} / \mathrm{U}_{\mathrm{A}}=$ 0.7の場合で衝突角が大きくなるに従い合流噴流の広がりは大きくなっておりまた衝笑点の

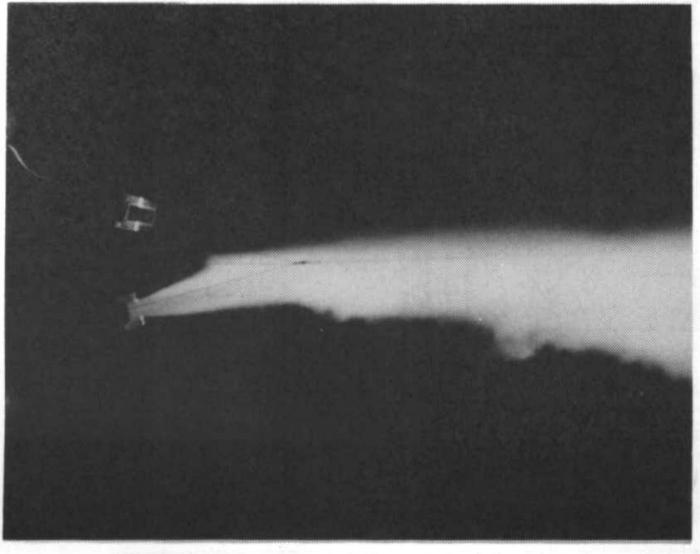

Photo. $1 \quad \alpha=30^{\circ} \quad \mathrm{U}_{\mathrm{B}} / \mathrm{U}_{\mathrm{A}}=1.1$

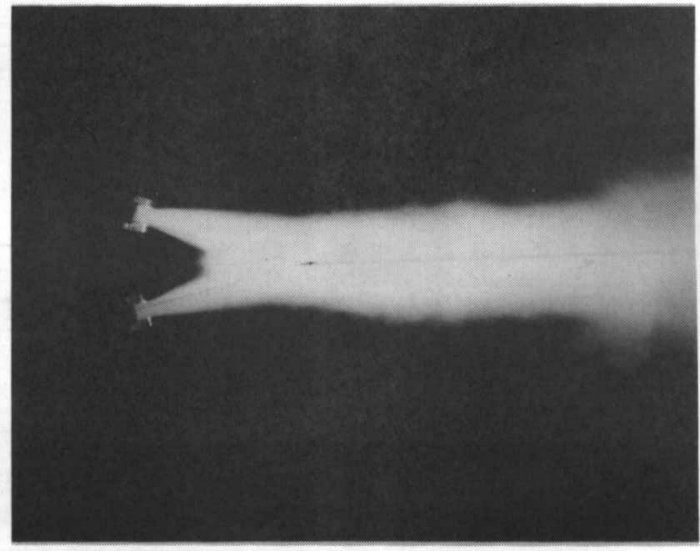

Photo. $2 \alpha=30^{\circ} \quad \mathrm{U}_{\mathrm{B}} / \mathrm{U}_{\mathrm{A}}=1.1$ 


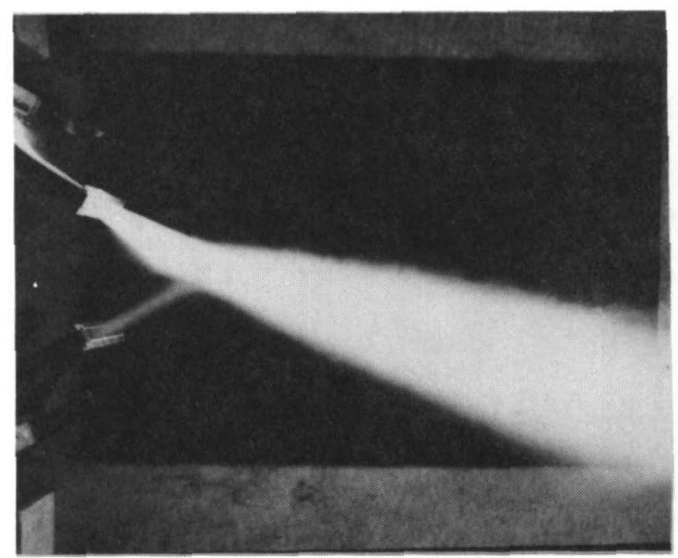

Photo. $3 \alpha=60^{\circ} \mathrm{U}_{\mathrm{B}} / \mathrm{U}_{\mathrm{A}}=1.3$

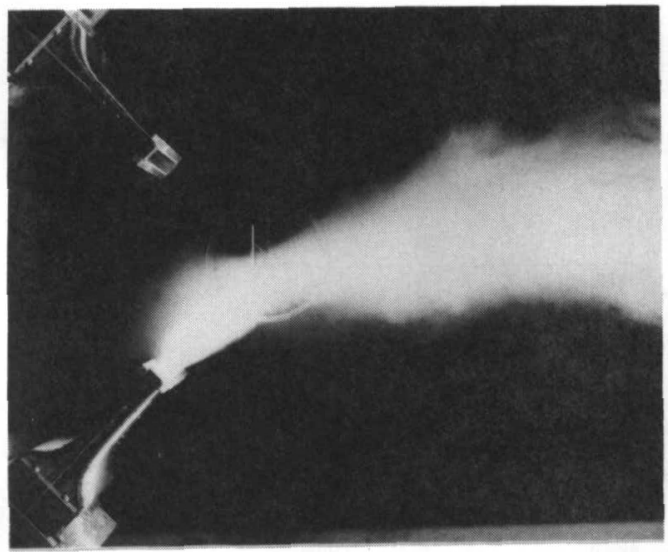

Photo. $5 \alpha=90^{\circ} \quad \mathrm{U}_{\mathrm{B}} / \mathrm{U}_{\mathrm{A}}=0.8$

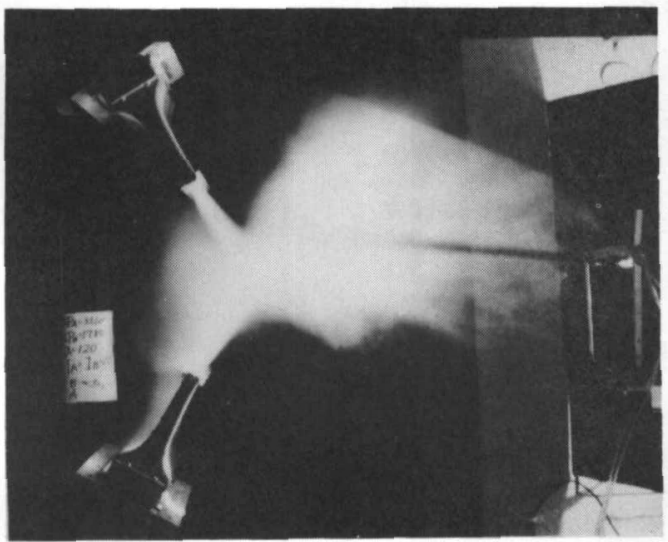

Photo. $7 \quad \alpha=120^{\circ} \quad \mathrm{U}_{\mathrm{B}} / \mathrm{U}_{\mathrm{A}}=0.7$

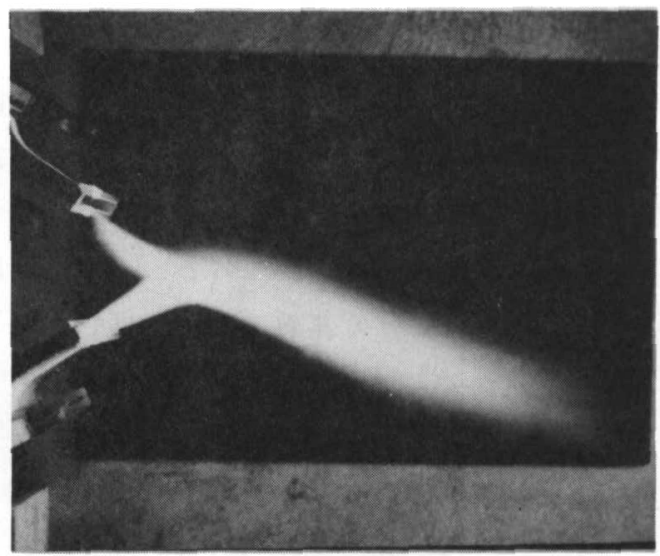

Photo. $4 \alpha=60^{\circ} \quad \mathrm{U}_{\mathrm{B}} / \mathrm{U}_{\mathrm{A}}=1.5$

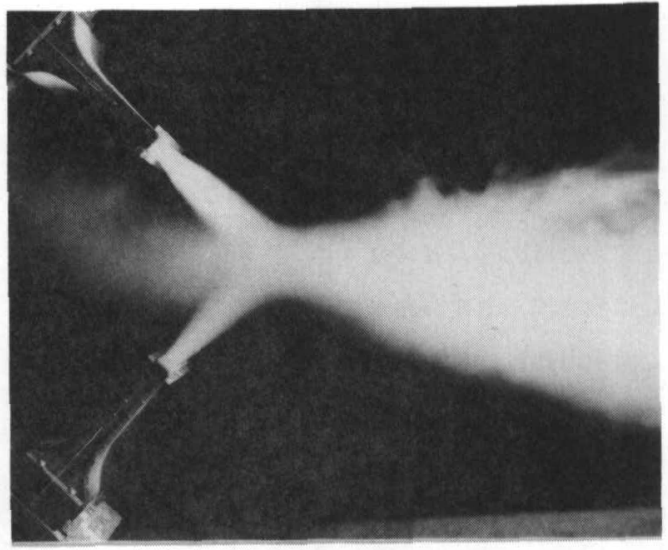

Photo. $6 \alpha=90^{\circ} \quad \mathrm{U}_{\mathrm{B}} / \mathrm{U}_{\mathrm{A}}=1.2$

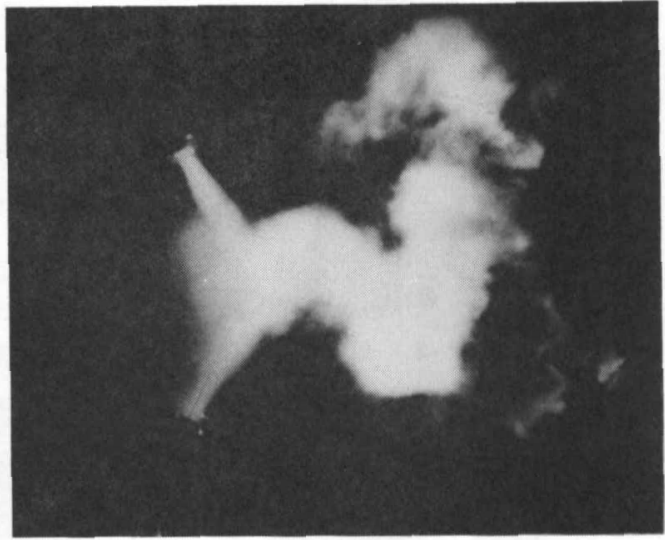

Photo. $8 \alpha=120^{\circ} \quad \mathrm{U}_{\mathrm{B}} / \mathrm{U}_{\mathrm{A}}=0.7$ 
上流測での流れの停流がみられる。写真 8 は写真 7 と同条件であるが A S A 3200 、シャッ タースピード1/250での撮影であり、この写真や目視観察により $\alpha=120$ では衝突点 付近からの脈動流が生していることが認められた。

$3 \cdot 2$ 濃度分布 目 2 は U $\mathrm{B}_{\mathrm{B}} / \mathrm{U}_{\mathrm{A}}=1$. 1 の時の濃度分布を示す。図中の実線は各断面に おける最大濃度点を結んだもので、一点顉線は絨何的な衝突点から書いた樶大速度の偏向線で 両ノズル出ロにおける連動量から算出したものである。

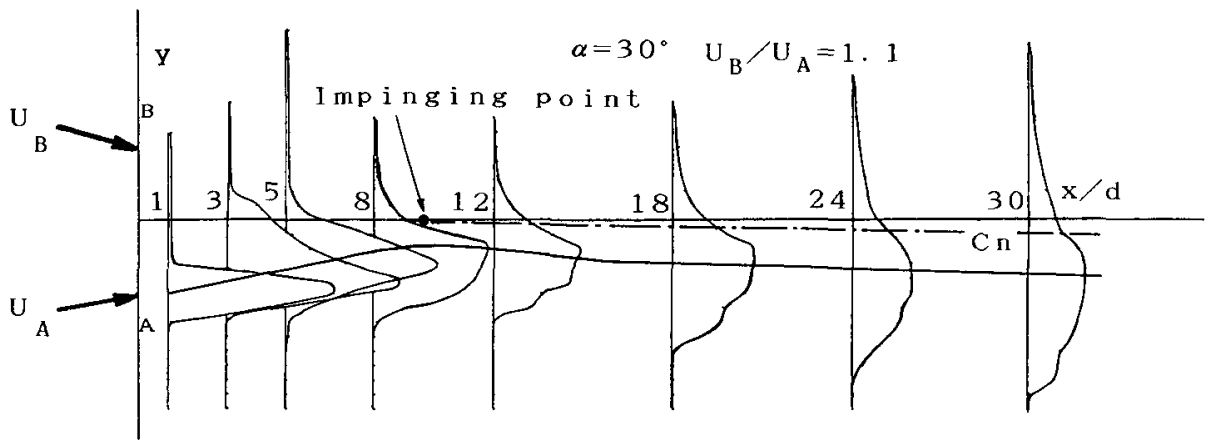

Fig. 2 Concentration distributions

図3は $\alpha=30^{\circ}$ で速度比

を変えた時の $\mathrm{x} / \mathrm{d}=24$ に おける無次元濃度分布である

、図中の破線はA 1 b e r t(6)

S○nらによる理論速度曲線

である。これらょり濃度分布 は相似形とは言いがたく、速 度分布二運動量移動に比べて 涨度分布二物質移動は遅れて いるものと考えられる。

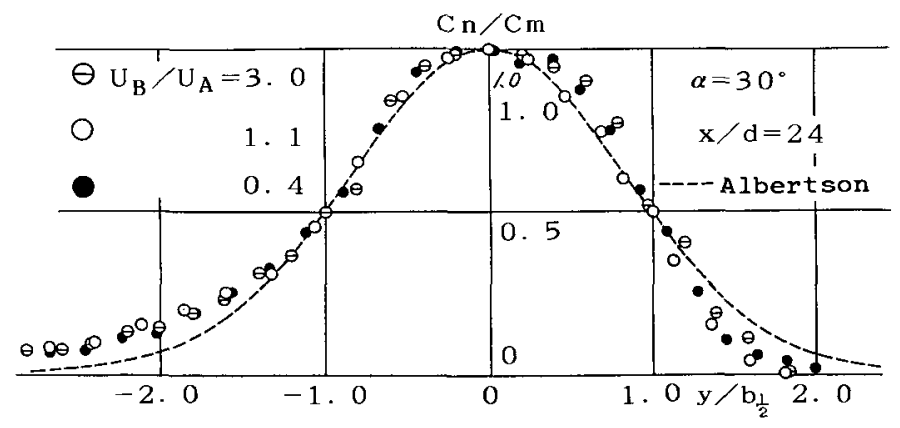

Fig. 3 Nondimensional Concentration distributions

4.あと がき

二つの三次元自由顀流を種タの角度と速度比で衝笑させた時の流れをトライアイス蒸気法に て可視化し、あわせて各断面の濃度分布む測定した。今後さらに詳耕な检討を加えていく予定 である。

参考文献

（1）尾崎. 原, 粁流体素子, 日刊工業新聞, ( 1967 )

（2）小林，日本機栈学会誌，92-842(平成元)，112

（3）岡本. 榎田、概論，47-419，B（昭56），1207

（4）藤本・新美・長田，權論，53-486，B（昭62），400

（5）大橋他 3 名，樍論，53-491，B（昭62），2000

(6) A l b e r t son, M. J., e t a l, P roc. S o c . C i v .

E $n g r s ., 74-10(1948), 1571$ 